\title{
Comorbidities Associated with Obstructive Sleep Apnea: a Retrospective Study
}

\author{
José Antonio Pinto ${ }^{1,2}$ Davi Knoll Ribeiro ${ }^{1,2}$ Andre Freitas da Silva Cavallini ${ }^{1,2}$ Caue Duarte ${ }^{1,2}$ \\ Gabriel Santos Freitas ${ }^{1,2}$
}

1 Department of Otolaryngology, Nucleo de Otorrinolaringologia e Cirurgia de Cabeça e Pescoço de São Paulo, São Paulo, SP, Brazil

2 Department of Otorhinolaringology, Hospital São Camilo, São Paulo, São Paulo, Brazil

Int Arch Otorhinolaryngol 2016;20:145-150.
Address for correspondence Davi Knoll Ribeiro, MD, Department of Otorrinolaringologia, Hospital São Camilo, Alameda dos

Nhambiquaras 159 - Moema São Paulo São Paulo 04090-010, Brazil (e-mail: orl.daviribeiro@gmail.com).

\begin{abstract}
Keywords

- apnea

- comorbidity

- polysomnography

- sleep

Introduction Obstructive sleep apnea (OSA) is characterized by partial or complete recurrent upper airway obstruction during sleep. OSA brings many adverse consequences, such as hypertension, obesity, diabetes mellitus, cardiac and encephalic alterations, behavioral, among others, resulting in a significant source of public health care by generating a high financial and social impact. The importance of this assessment proves to be useful, because the incidence of patients with comorbidities associated with AOS has been increasing consistently and presents significant influence in natural disease history.

Objective The objective of this study is to assess major comorbidities associated with obstructive sleep apnea (OSA) and prevalence in a group of patients diagnosed clinically and polysomnographically with OSA.

Methods This is a retrospective study of 100 charts from patients previously diagnosed with OSA in our service between October 2010 and January 2013.

Results We evaluated 100 patients with OSA ( 84 men and 16 women) with a mean age of 50.05 years (range 19-75 years). The prevalence of comorbidities were hypertension (39\%), obesity (34\%), depression (19\%), gastroesophageal reflux disease (GERD) (18\%), diabetes mellitus (15\%), hypercholesterolemia (10\%), asthma (4\%), and no comorbidities (33\%). Comorbidities occurred in $56.2 \%$ patients diagnosed with mild OSA, $67.6 \%$ with moderate OSA, and $70 \%$ of patients with severe OSA.

Conclusion According to the current literature data and the values obtained in our paper, we can correlate through expressive values obesity with OSA and their apnea hypopnea index $(\mathrm{AHI})$ values. However, despite significant prevalence of OSA with other comorbidities, our study could not render expressive significance values able to justify their correlations.
\end{abstract}

\section{Introduction}

Obstructive sleep apnea (OSA) is characterized by partial or complete recurrent upper airway obstruction during sleep, resulting in periods of apnea, oxyhemoglobin desaturation, and frequent night awakenings with excessive daytime sleepiness as a consequence, ${ }^{1}$ reducing performance at work and in social activities in many cases. According to Young, the prevalence of OSA in adults between 30 to 60 years old ranges from $2 \%$ in women up to $4 \%$ in men. ${ }^{2}$ A Brazilian study revealed that the incidence of OSA is $\sim 32.8 \%$ in the population of São Paulo. ${ }^{3}$ received

August 11, 2015

accepted

December 6, 2015

published online

March 10, 2016
DOI http://dx.doi.org/

10.1055/s-0036-1579546. ISSN $1809-9777$.
Copyright $\odot 2016$ by Thieme Publicações License terms Ltda, Rio de Janeiro, Brazil 
The prevalence of OSA associated with high rates of morbidity and mortality increases with age and the peak occurs at $\sim 55$ years, being more prevalent in males at a ratio of 2:1. It is more common in women in the postmenopausal period. ${ }^{4}$

OSA pathophysiology has not been fully elucidated. We know that during respiratory events there is a fall in oxygen saturation, causing activation of the baroreflex, triggering a response of the sympathetic nervous system, adrenergic discharge leading to tachycardia and hypertension peaks. This process repeats itself many times during sleep in apneic patients, leading to hypersensitivity peripheral quimioreflex. This exaggerated response even in normoxia, leads to long-term dysfunction of the baroreflex, increased adrenergic discharge, cardiovascular dysfunction, systemic inflammation, and metabolic deregulation with insulin resistance and diabetes mellitus type II. ${ }^{5}$

OSA brings many adverse consequences, such as hypertension, obesity, diabetes mellitus, cardiac and encephalic alterations, behavioral, among others, resulting in significant source of public health care by generating a high financial and social impact. These comorbidities are associated with increased mortality in patients with OSA compared with the general population of the same age group. ${ }^{6}$

The risk factors for obstructive sleep apnea are obesity, age, gender, menopause, craniofacial abnormalities, smoking, alcohol use, and family history. ${ }^{7}$

OSA is a systemic disease that causes an increase in inflammatory cytokines, tumor necrosis factor $\alpha$ (TNF- $\alpha$ ), interleukin- 6 (IL-6), increased insulin resistance, and glucose intolerance. ${ }^{8-10}$

Cardiovascular diseases are now the major cause of mortality in the world. ${ }^{11}$ Several studies confirm the importance of factors such as smoking, high levels of LDL-cholesterol, low HDLcholesterol levels, diabetes mellitus, hypertension, family history, obesity, physical inactivity, central obesity, metabolic syndrome, and alcohol intake in the genesis of atherosclerosis and their clinical complications. ${ }^{12-14}$ In addition to these factors, there has been recent evidence of increased cardiovascular mortality in patients with OSA. ${ }^{15,16}$ Other comorbidities also associated with OSA are: depression, asthma, and GERD.

The prevalence of GERD in OSA patients is significantly higher than the general population. Recent studies have shown that treatment with a continuous positive airway pressure (CPAP) device significantly reduces the symptoms of GERD and the exposure of acid $\mathrm{pH}$ in the esophagus as well as improves the number of awakenings and apnea indexes. ${ }^{17}$

This work aims to analyze the prevalence of major comorbidities associated with OSA in a selected group of patients with a clinical and polysomnography diagnosis of OSA. The importance of this assessment proves to be useful, because the incidence of patients with comorbidities associated with AOS has been increasing consistently and presents significant influence in natural disease history.

\section{Methods}

Our study received approval from the Research Ethics Committee, registered under number 437-760. We delineated an observational retrospective cross-sectional study. We carried out the evaluation by reviewing the protocol of patients with
OSA in the Otorhinolaryngology service from October 2010 to January 2013.

The evaluation protocol included anamnesis, complete physical examination, anthropometric measurements (weight, body mass index (BMI), neck circumference (NC), waist circumference (WC), pelvic circumference (CP)), and complete otorhinolaryngological exam with Nasofibrolaryngoscopy and Polysomnography type I made in the sleep laboratory with technical assistance enabled. We considered obesity a BMI $>30$.

We classified the degree of apnea according to the apnea hypopnea index (AHI in: mild ( $\geq 5$ to $<15$ events / hour), moderate ( $\geq 15$ to $<30$ events / hour), and severe ( $\geq 30$ events / hour).

All patients filled out questionnaires with respect to diseases of the cardiovascular, respiratory, endocrine, neurological, psychiatric, genitourinary, gastrointestinal, and metabolic systems. Comorbidity diagnosis relied solely on the response to our questionnaire, and when the answer was positive as to the patient having comorbidity, the patient described the medications in use.

Inclusion criteria were patients in the OSA ambulatory cohort, patients with complete protocols, patients aged between 18 and 80 years, and patients of both genders. Exclusion criteria were patients with tumors and / or polyps in the upper airway, patients with craniofacial deformity (craniofacial deformity may already be an isolated change factor for AHI regardless of associated comorbidities), patients with previous history of airway surgery and / or abdominal surgery.

For data analysis, we compared proportions between three independent groups and applied the Fisher-Freeman-Halton exact test. When we observed significant difference, we proceeded to multiple comparisons of proportions via permutation tests. We described categorical variables by counts and proportions. Quantitative variables with normal and asymmetric distribution were described as mean \pm standard deviation and median (interquartile range), respectively. We assessed normality by visual inspection of histograms. The $R$ (R Foundation, Vienna, Austria) software was used for statistical data analysis. All significance probabilities presented are the bilateral type and values less than 0.05 were considered statistically significant.

\section{Results}

We evaluated one hundred patients: 84 males and 16 females, mean age of 50.05 years, ranging from 19 to 75 years. BMI ranged from 20.7 to 50.81 with an average of 28.95. - Table 1 shows the measured anthropometric measurements.

We divided the sample in 3 independent groups according to the AHI using a cutoff: mild apnea ( $\geq 5$ to $<15$ events / hour), moderate apnea ( $\geq 15$ to $<30$ events / hour), and severe apnea ( $\geq 30$ events / hour). The AHI ranged from 6.7 to 98.59 with an average of 35.19; 16 patients had mild AHI, 34 patients had moderate IAH, and 50 patients had severe AHI. After splitting the sample, we analyzed comorbidities (Obesity, Hypertension, Depression, Gastroesophageal Reflux Disease, Diabetes Mellitus, Hypercholesterolemia, and Asthma) separately in relation to AHI using Fisher-Freeman-Halton exact test to determine whether 
Table 1 Descriptive variables

\begin{tabular}{|l|l|l|l|l|}
\hline Variable & Minimum & Maximum & Average & $\begin{array}{l}\text { Standard } \\
\text { deviation }\end{array}$ \\
\hline Age & 19 & 75 & 50.05 & \pm 12.86 \\
\hline Weight & 51.50 & 140.00 & 89.40 & \pm 17.10 \\
\hline BMI & 20.70 & 50.81 & 28.95 & \pm 4.95 \\
\hline NC & 32.00 & 51.00 & 41.20 & \pm 3.66 \\
\hline AC & 53.00 & 146.00 & 101.87 & \pm 14.52 \\
\hline PC & 48.00 & 153.00 & 105.87 & \pm 12.70 \\
\hline
\end{tabular}

Abbreviations: AC, abdominal circumference; BMI, Body Mass Index; NC, neck circumference; $\mathrm{PC}$, pelvic circumference.

there was significant difference in proportions between the three groups (Fisher-Freeman-Halton test, $p=0.010$ ). Comorbidities were associated in $56.2 \%$ patients diagnosed with mild OSA, in $67.6 \%$ with moderate OSA, and in $70 \%$ of patients with severe OSA. The prevalence in relation to associated comorbidities were: obesity (32\%), 30 men and 2 women, among them, 23 had severe OSA, 7 moderate OSA and 2 mild OSA, hypertension (39\%), 38 men and 1 woman, among them, 23 had severe OSA, 12 moderate OSA and 4 mild OSA; depression (19\%), 16 men and 3 women, among them, 7 had severe OSA, 7 moderate OSA and 5 mild OSA; gastroesophageal reflux disease (18\%), 10 patients had severe OSA, 7 moderate OSA and 1 mild OSA; diabetes mellitus (15\%), among them, 9 had severe OSA, 5 moderate OSA, and 1 mild OSA 1; hypercholesterolemia (10\%), 6 of them had severe OSA and 4 moderate OSA; and asthma (4\%) all of them had severe OSA. - Table 2 shows the final comparative results.

For $p$ less than 0.05 on the Fisher-Freeman-Halton test (significant difference observed), we used the permutation test for multiple comparisons of proportions to find out whether there was significant difference between the degrees of apnea. We only observed significant $p$ for obesity ( $p=0.013)$ and, after applying multiple comparisons, there was no difference in obesity proportion between mild AHI when compared with those with moderate AHI (12.5\% versus $20.6 \% ; p=0.849$; permutation test); the obesity rate was statistically lower in the comparison between the mild AHI group and severe AHI group (12.5\% versus $46.0 \% ; p=0.035$; permutation test), and between moderate AHI group when compared with severe AHI group (20.6\% versus $46.0 \%$; $p=0.040$; permutation test). - Table 3 shows the results of multiple comparisons for obesity proportion.

\section{Discussion}

The importance of OSA and its associated comorbidities in otorhinolaryngology has increased considerably in recent years. Present among the main complaints in specialty clinics, this disease causes chronic inflammation and decrease in quality of life.

The prevalence of OSA is strongly associated to overweight and obesity in cross-sectional and clinical studies. ${ }^{18-24}$ Obesity is known to be a cause of AOS and is likely to be a consequence thereof. This complexity makes it especially

Table 3 Multiple Comparisons - Obesity in relation to the apnea hypopnea index

\begin{tabular}{|l|l|l|}
\hline Variable & Comparison between $\mathrm{AHI}$ index & $P$-Value \\
\hline Obesity & $5 \leq \mathrm{AlH}<15$ vs $15 \leq \mathrm{AlH}<30$ & 0.849 \\
\hline Obesity & $5 \leq \mathrm{AlH}<15$ vs $\mathrm{AlH} \geq 30$ & 0.035 \\
\hline Obesity & $15 \leq \mathrm{AlH}<30$ vs $\mathrm{AlH} \geq 30$ & 0.040 \\
\hline
\end{tabular}

Abbreviations: $\mathrm{AHI}$, apnea-hypopnea index.

Table 2 Prevalence of comorbidities x OSA severity

\begin{tabular}{|c|c|c|c|c|c|c|}
\hline \multicolumn{2}{|l|}{ Variable } & \multirow{2}{*}{$\begin{array}{l}\text { Mild OSA } \\
\mathrm{N}=16 \\
2(12.5 \%) \\
\end{array}$} & \multirow{2}{*}{$\begin{array}{l}\text { Moderate OSA } \\
\mathrm{N}=34 \\
7(20.6 \%) \\
\end{array}$} & \multirow{2}{*}{$\begin{array}{l}\text { Severe OSA } \\
\mathrm{N}=50\end{array}$} & \multirow{2}{*}{$\begin{array}{l}\text { Total } \\
\mathrm{N}=100 \\
32(32.0 \%)\end{array}$} & \multirow{2}{*}{$\begin{array}{c}P \text {-Value } \\
0.010^{3}\end{array}$} \\
\hline Obesity & Yes & & & & & \\
\hline & No & $14(87.5 \%)$ & $27(79.4 \%)$ & $27(54.0 \%)$ & $68(68.0 \%)$ & \\
\hline \multirow[t]{2}{*}{ Hypertension } & Yes & $4(25.0 \%)$ & $12(35.3 \%)$ & $23(46.0 \%)$ & $39(39.0 \%)$ & \multirow[t]{2}{*}{$0.291^{3}$} \\
\hline & No & $12(75.0 \%)$ & $22(64.7 \%)$ & $27(54.0 \%)$ & $61(61.0 \%)$ & \\
\hline \multirow[t]{2}{*}{ Depression } & Yes & $5(31.3 \%)$ & $7(20.6 \%)$ & $7(14.0 \%)$ & $19(19.0 \%)$ & \multirow[t]{2}{*}{$0.273^{3}$} \\
\hline & No & $11(68.8 \%)$ & $27(79.4 \%)$ & $43(86.0 \%)$ & $81(81 \%)$ & \\
\hline \multirow[t]{2}{*}{ GERD } & Yes & $1(6.3 \%)$ & $7(20.6 \%)$ & $10(20.0 \%)$ & $18(18.0 \%)$ & \multirow[t]{2}{*}{$0.467^{3}$} \\
\hline & No & $15(93.8 \%)$ & $27(79.4 \%)$ & $40(80.0 \%)$ & $82(82.0 \%)$ & \\
\hline \multirow[t]{2}{*}{$\mathrm{DM}$} & Yes & $1(6.3 \%)$ & $5(14.7 \%)$ & $9(18.0 \%)$ & $15(15.0 \%)$ & \multirow[t]{2}{*}{$0.601^{3}$} \\
\hline & No & $15(93.8 \%)$ & $29(85.3 \%)$ & $41(82.0 \%)$ & $85(85.0 \%)$ & \\
\hline \multirow[t]{2}{*}{ Hypercholesterolemia } & Yes & $0(0.0 \%)$ & $4(11.8 \%)$ & $6(12.0 \%)$ & $10(10.0 \%)$ & \multirow[t]{2}{*}{$0.442^{3}$} \\
\hline & No & $16(100.0 \%)$ & $30(88.2 \%)$ & $44(88.0 \%)$ & $90(90.0 \%)$ & \\
\hline \multirow[t]{2}{*}{ Asthma } & Yes & $0(0.0 \%)$ & $0(0.0 \%)$ & $4(8.0 \%)$ & $4(4.0 \%)$ & \multirow[t]{2}{*}{$0.214^{3}$} \\
\hline & No & $16(100.0 \%)$ & $34(100.0 \%)$ & $46(92.0 \%)$ & $96(96.0 \%)$ & \\
\hline
\end{tabular}

Abbreviations: DM, Diabetes Mellitus; GERD, Gastroesophageal Reflux Disease; N, number of individuals. 
difficult to interpret the relationship between the two conditions and between OSA and its relation to cardiovascular disease and metabolic disorders. ${ }^{18,19,25-28}$ In a random sample of middle-aged patients, taken from a cohort study of Wisconsin, 1-point increase in the standard deviation obesity was associated with an increase of 4 times the risk of sleep apnea. ${ }^{20}$

According to a survey conducted by the Brazilian Ministry of Health in 2012, with retrospective of six years, the obese percentage increased from $11.6 \%$ to $17.4 \% .{ }^{29}$ In the current study, the prevalence of obesity in OSA patients was $32 \%$, almost double that of the general population. Moreover, it was the only comorbidity which obtained significant value $(p<0.05)$ confirming the direct relationship of its prevalence to OSA and correlating directly with the severity.

Previous clinical studies indicate that OSA may be associated with hypertension and $\sim 50 \%$ of patients end up having the two associated pathologies. ${ }^{30-32}$ Several cross-sectional studies suggest an independent association between OSA and hypertension. ${ }^{33,34}$ Discrepant findings were observed in the Sleep Heart Health Study, a prospective cohort study to monitoring of cardiovascular outcome in patients diagnosed with sleep disorders. The $p$ value for hypertension was significant with the increase of the AHI, however, this relationship was attenuated and was not significant after a correlation with BMI, suggesting that much of the relationship between AHI and hypertension resulted from obesity. ${ }^{35}$

In relation to arterial hypertension, the most recent data in Brazil, from 2012, showed that average prevalence of hypertension in the Brazilian population was $24.3 \%{ }^{29}$ In our study, $39 \%$ of patients had hypertension, a higher rate than the general population and a higher rate than the overall percentage to obese patients, however there was no significant correlation value between OSA and hypertension. One explanation for these results is that the highest difference between the proportions of hypertension variable was $25.0 \%$ (mild $\mathrm{AHI}$ ) versus $46.0 \%$ (severe $\mathrm{AHI}$ ); a difference of $21 \%$ is not enough to observe a statistically significant difference, whereas the obesity variable produced a difference of $25.4 \%$, enough to produce a statistically significant difference. In a study where one of the groups have a significantly reduced $\mathrm{N}$ (mild $\mathrm{AHI}, N=16$ ), the differences between the values must be greater to observe statistical significance.

Psychiatric symptoms or associated disorders with OSA include depression, anxiety, post-traumatic stress disorder, among others. ${ }^{36-39}$ They seem to be more common and more severe in females with OSA than in males. ${ }^{38}$ Symptoms of depression, though prevalent in OSA do not correlate with severity. ${ }^{38,40,41}$ In our study, we found $19 \%$ of patients with depressive symptoms using medication, with no significant differences between the AHI values.

Several authors have evaluated the possible association between GERD and OSA. ${ }^{42-47}$ However, only a single study confirmed the direct relationship between the two diseases. ${ }^{47}$ In our study, $18 \%$ of OSA patients were diagnosed with GERD, with no correlation to the severity of the apnea.

The association between OSA and type II DM is recognized. ${ }^{48,49}$ Cross-sectional studies suggest that up to $30 \%$ of patients with OSA have type II DM and up to $86 \%$ of obese patients with type II DM have OSA. ${ }^{24,50-52}$ However, due to the presence of variables, especially obesity, research has not demonstrated a direct causal relationship between OSA and alterations in glucose metabolism. ${ }^{53,54}$ Fifteen per cent of our patients had DM associated with OSA, lacking evidence of correlation between AHI and DM type II.

Data from Sleep Heart Health Study indicated that total cholesterol levels were associated with AHI values, after correlation with age and BMI. ${ }^{23}$ Most of the other clinical studies that discuss the relationship between OSA and dyslipidemia have a reduced number of participants; however, when comparing studies of dyslipidemia values with individuals without OSA, these studies have shown an increase in lipid abnormalities in patients with OSA. ${ }^{55-57}$ The AHI was the main determinant for cholesterol dysfunction. These observations suggest that cholesterol tends to be altered in patients with OSA and partly contributes to increase the cardiovascular risk. ${ }^{58}$ In our study, $10 \%$ of all patients had hypercholesterolemia and all of them had moderate or severe AHI, suggesting a correlation between AHI and hypercholesterolemia, although no statistical significance value was found.

Several publications have discussed the relationship between asthma and OSA. ${ }^{59-63}$ Salles et al reported that OSA is prevalent in patients with asthma and is associated with disease severity. Asthma is associated with acute and chronic inflammation that affects the respiratory muscles, including upper airway dilators. ${ }^{64}$ The biological mechanism that correlates asthma to OSA would be the fact that the inflammation of the upper airways caused by asthma would facilitate the collapse of the muscles favoring OSA. National Asthma Education and Prevention Program recommends screening of OSA in patients with asthma because treatment of OSA has proven to be effective in improving symptoms of asthma. ${ }^{65,66}$ In our study, only $4 \%$ of patients had asthma associated with OSA, although it has not presented expressive values; only patients with severe apnea had associated asthma.

There are limitations to this study. The first is due to a modest sample of patients ( $n=100)$, second, we did not rely on a control group without OSA and correlate with associated comorbidities.

We identified a statistically significant relationship between OSA and obesity, noting that obesity is more prevalent the higher the AHI. In relation to other comorbidities, we could not obtain statistical significance values, however a higher percentage of patients with associated comorbidities have a high AHI. Based on data obtained in our work and from the current literature, we can correlate some aspects between OSA and associated comorbidities, however, further research on this topic may be able to reveal more obvious correlations between the pathologies.

\section{Conclusion}

The causal relationship of the OAS with the associated comorbidities has gained notoriety in the literature with the emergence of prospective studies using polysomnography in large 
numbers of patients. Current data supports OSA as an independent risk factor for the emergence of comorbidities. Patients with risk factors for sleep apnea should be properly investigated, since the failure to identify the sleep disorder may contribute to therapeutic failure in the treatment of comorbidities. Based on the current literature data and the values found in our work, we can correlate with significance obesity values with OSA and their AHI values; however, despite significant prevalence of OSA with other comorbidities, we cannot rely on significant values in our study to justify their correlations. Research with control group and a higher number of cases are necessary for further investigations and correlations.

\section{References}

1 Cintra FD. Obstrutive sleep apnea as a risk factor for cardiovascular disease. . Rev Bras Hipertensão 2013;20(1):7-9

2 Young T, Palta M, Dempsey J, Skatrud J, Weber S, Badr S. The occurrence of sleep-disordered breathing among middle-aged adults. N Engl J Med 1993;328(17):1230-1235

3 Tufik S, Santos-Silva R, Taddei JA, Bittencourt LR. Obstructive sleep apnea syndrome in the Sao Paulo Epidemiologic Sleep Study. Sleep Med 2010;11(5):441-446

4 Kapsimalis F, Kryger M. Sleep breathing disorders in the U.S. female population. J Womens Health (Larchmt) 2009;18(8): 1211-1219

5 Jennum P, Sjøl A. Epidemiology of snoring and obstructive sleep apnoea in a Danish population, age 30-60. J Sleep Res 1992;1(4): 240-244

6 Marrone O, Lo Bue A, Salvaggio A, Dardanoni G, Insalaco G. Comorbidities and survival in obstructive sleep apnoea beyond the age of 50. Eur J Clin Invest 2013;43(1):27-33

7 Punjabi NM. The epidemiology of adult obstructive sleep apnea. Proc Am Thorac Soc 2008;5(2):136-143

8 Aurora RN, Punjabi NM. Obstructive sleep apnoea and type 2 diabetes mellitus: a bidirectional association. Lancet Respir Med 2013;1(4):329-338

9 Vgontzas AN, Papanicolaou DA, Bixler EO, Kales A, Tyson K, Chrousos GP. Elevation of plasma cytokines in disorders of excessive daytime sleepiness: role of sleep disturbance and obesity. J Clin Endocrinol Metab 1997;82(5):1313-1316

10 Fried SK, Bunkin DA, Greenberg AS. Omental and subcutaneous adipose tissues of obese subjects release interleukin-6: depot difference and regulation by glucocorticoid. J Clin Endocrinol Metab 1998;83(3):847-850

11 Moreira RO, Santos RD, Martinez L, et al. [Lipid profile of patients with increased risk for cardiovascular events in daily clinical practice]. Arq Bras Endocrinol Metabol 2006;50(3): 481-489

12 Kannel WB, D'Agostino RB, Wilson PW, Belanger AJ, Gagnon DR. Diabetes, fibrinogen, and risk of cardiovascular disease: the Framingham experience. Am Heart J 1990;120(3):672-676

13 Kannel WB. Lessons from curbing the coronary artery disease epidemic for confronting the impending epidemic of heart failure. Med Clin North Am 2004;88(5):1129-1133, ix

14 Avezum A, Piegas LS, Pereira JC. Risk factors associated with acute myocardial infarction in the São Paulo metropolitan region: a developed region in a developing country. Arq Bras Cardiol 2005; 84(3):206-213

15 Marin JM, Carrizo SJ, Vicente E, Agusti AG. Long-term cardiovascular outcomes in men with obstructive sleep apnoea-hypopnoea with or without treatment with continuous positive airway pressure: an observational study. Lancet 2005;365(9464): 1046-1053
16 Cintra FD, Poyares D, Guilleminault C, Carvalho AC, Tufik S, de Paola AA. [Cardiovascular comorbidities and obstructive sleep apnea]. Arq Bras Cardiol 2006;86(6):399-407

17 Shepherd KL, James AL, Musk AW, Hunter ML, Hillman DR, Eastwood PR. Gastro-oesophageal reflux symptoms are related to the presence and severity of obstructive sleep apnoea. J Sleep Res 2011;20(1 Pt 2):241-249

18 Schwartz AR, Patil SP, Laffan AM, Polotsky V, Schneider H, Smith PL. Obesity and obstructive sleep apnea: pathogenic mechanisms and therapeutic approaches. Proc Am Thorac Soc 2008;5(2): 185-192

19 Shah N, Roux F. The relationship of obesity and obstructive sleep apnea. Clin Chest Med 2009;30(3):455-465, vii vii

20 Young T, Palta M, Dempsey J, Skatrud J, Weber S, Badr S. The occurrence of sleep-disordered breathing among middle-aged adults. N Engl J Med 1993;328(17):1230-1235

21 Nieto FJ, Young TB, Lind BK, et al. Association of sleep-disordered breathing, sleep apnea, and hypertension in a large communitybased study. Sleep Heart Health Study. JAMA 2000;283(14): 1829-1836

22 Peppard PE, Young T, Palta M, Dempsey J, Skatrud J. Longitudinal study of moderate weight change and sleep-disordered breathing. JAMA 2000;284(23):3015-3021

23 Newman AB, Nieto FJ, Guidry U, et al; Sleep Heart Health Study Research Group. Relation of sleep-disordered breathing to cardiovascular disease risk factors: the Sleep Heart Health Study. Am J Epidemiol 2001;154(1):50-59

24 Foster GD, Sanders MH, Millman R, et al; Sleep AHEAD Research Group. Obstructive sleep apnea among obese patients with type 2 diabetes. Diabetes Care 2009;32(6):1017-1019

25 Pillar G, Shehadeh N. Abdominal fat and sleep apnea: the chicken or the egg? Diabetes Care 2008;31(Suppl 2):S303-S309

26 Vgontzas AN. Does obesity play a major role in the pathogenesis of sleep apnoea and its associated manifestations via inflammation, visceral adiposity, and insulin resistance? Arch Physiol Biochem 2008;114(4):211-223

27 Dempsey JA, Veasey SC, Morgan BJ, O'Donnell CP. Pathophysiology of sleep apnea. Physiol Rev 2010;90(1):47-112

28 Schwartz AR, Patil SP, Squier S, Schneider H, Kirkness JP, Smith PL. Obesity and upper airway control during sleep. J Appl Physiol (1985) 2010;108(2):430-435

29 Brasil. Ministério da Saúde. Secretaria de Vigilância em Saúde. Departamento de Vigilância de Doenças e Agravos não Transmissíveis e Promoção de Saúde. Vigitel Brasil 2012: vigilância de fatores de risco e proteção para doenças crônicas por inquérito telefônico - Brasília: Ministério da Saúde, 2013

30 Millman RP, Redline S, Carlisle CC, Assaf AR, Levinson PD. Daytime hypertension in obstructive sleep apnea. Prevalence and contributing risk factors. Chest 1991;99(4):861-866

31 Worsnop CJ, Naughton MT, Barter CE, Morgan TO, Anderson AI, Pierce RJ. The prevalence of obstructive sleep apnea in hypertensives. Am J Respir Crit Care Med 1998;157(1):111-115

32 Logan AG, Perlikowski SM, Mente A, et al. High prevalence of unrecognized sleep apnoea in drug-resistant hypertension. J Hypertens 2001;19(12):2271-2277

33 Lavie P, Herer P, Hoffstein V. Obstructive sleep apnoea syndrome as a risk factor for hypertension: population study. BMJ 2000; 320(7233):479-482

34 Nieto FJ, Young TB, Lind BK, et al. Association of sleep-disordered breathing, sleep apnea, and hypertension in a large communitybased study. Sleep Heart Health Study. JAMA 2000;283(14): 1829-1836

35 O'Connor GT, Caffo B, Newman AB, et al. Prospective study of sleep-disordered breathing and hypertension: the Sleep Heart Health Study. Am J Respir Crit Care Med 2009;179(12):1159-1164 36 Sateia MJ. Update on sleep and psychiatric disorders. Chest 2009; 135(5):1370-1379 
37 Sharafkhaneh A, Giray N, Richardson P, Young T, Hirshkowitz M. Association of psychiatric disorders and sleep apnea in a large cohort. Sleep 2005;28(11):1405-1411

38 McCall WV, Harding D, O'Donovan C. Correlates of depressive symptoms in patients with obstructive sleep apnea. J Clin Sleep Med 2006;2(4):424-426

39 Saunamäki T, Jehkonen M. Depression and anxiety in obstructive sleep apnea syndrome: a review. Acta Neurol Scand 2007;116(5): 277-288

40 Dominici M, Gomes MdaM. Obstructive sleep apnea (OSA) and depressive symptoms. Arq Neuropsiquiatr 2009;67(1):35-39

41 Macey PM, Woo MA, Kumar R, Cross RL, Harper RM. Relationship between obstructive sleep apnea severity and sleep, depression and anxiety symptoms in newly-diagnosed patients. PLoS ONE 2010;5(4):e10211

42 Suganuma N, Shigedo Y, Adachi $\mathrm{H}$, et al. Association of gastroesophageal reflux disease with weight gain and apnea, and their disturbance on sleep. Psychiatry Clin Neurosci 2001;55(3): 255-256

43 Gislason T, Janson C, Vermeire P, et al. Respiratory symptoms and nocturnal gastroesophageal reflux: a population-based study of young adults in three European countries. Chest 2002;121(1): 158-163

44 Green BT, Broughton WA, O'Connor JB. Marked improvement in nocturnal gastroesophageal reflux in a large cohort of patients with obstructive sleep apnea treated with continuous positive airway pressure. Arch Intern Med 2003;163(1):41-45

45 Oztürk O, Oztürk L, Ozdogan A, Oktem F, Pelin Z. Variables affecting the occurrence of gastroesophageal reflux in obstructive sleep apnea patients. Eur Arch Otorhinolaryngol 2004;261(4):229-232

46 Berg S, Hoffstein V, Gislason T. Acidification of distal esophagus and sleep-related breathing disturbances. Chest 2004;125(6): 2101-2106

47 Konermann M, Radü HJ, Teschler H, Rawert B, Heimbucher J, Sanner BM. Interaction of sleep disturbances and gastroesophageal reflux in chronic laryngitis. Am J Otolaryngol 2002;23(1): 20-26

48 Tasali E, Leproult R, Spiegel K. Reduced sleep duration or quality: relationships with insulin resistance and type 2 diabetes. Prog Cardiovasc Dis 2009;51(5):381-391

49 Shaw JE, Punjabi NM, Wilding JP, Alberti KG, Zimmet PZ; International Diabetes Federation Taskforce on Epidemiology and Prevention. Sleep-disordered breathing and type 2 diabetes: a report from the International Diabetes Federation Taskforce on Epidemiology and Prevention. Diabetes Res Clin Pract 2008;81(1):2-12

50 Elmasry A, Lindberg E, Berne C, et al. Sleep-disordered breathing and glucose metabolism in hypertensive men: a population-based study. J Intern Med 2001;249(2):153-161
51 Einhorn D, Stewart DA, Erman MK, Gordon N, Philis-Tsimikas A, Casal E. Prevalence of sleep apnea in a population of adults with type 2 diabetes mellitus. Endocr Pract 2007;13(4):355-362

52 Laaban JP, Daenen S, Léger D, et al. Prevalence and predictive factors of sleep apnoea syndrome in type 2 diabetic patients. Diabetes Metab 2009;35(5):372-377

53 Tasali E, Ip MS. Obstructive sleep apnea and metabolic syndrome: alterations in glucose metabolism and inflammation. Proc Am Thorac Soc 2008;5(2):207-217

54 Lévy P, Bonsignore MR, Eckel J. Sleep, sleep-disordered breathing and metabolic consequences. Eur Respir J 2009;34(1):243-260

55 McArdle N, Hillman D, Beilin L, Watts G. Metabolic risk factors for vascular disease in obstructive sleep apnea: a matched controlled study. Am J Respir Crit Care Med 2007;175(2):190-195

56 Coughlin SR, Mawdsley L, Mugarza JA, Calverley PM, Wilding JP. Obstructive sleep apnoea is independently associated with an increased prevalence of metabolic syndrome. Eur Heart J 2004; 25(9):735-741

57 Roche F, Sforza E, Pichot V, et al; PROOF Study Group. Obstructive sleep apnoea/hypopnea influences high-density lipoprotein cholesterol in the elderly. Sleep Med 2009;10(8):882-886

58 Tan KC, Chow WS, Lam JC, et al. HDL dysfunction in obstructive sleep apnea. Atherosclerosis 2006;184(2):377-382

59 Salles C, Terse-Ramos R, Souza-Machado A, Cruz ÁA. Obstructive sleep apnea and asthma. J Bras Pneumol 2013;39(5):604-612

60 Prasad B, Nyenhuis SM, Weaver TE. Obstructive sleep apnea and asthma: associations and treatment implications. Sleep Med Rev 2014;18(2):165-171

61 Puthalapattu S, Ioachimescu OC. Asthma and obstructive sleep apnea: clinical and pathogenic interactions. J Investig Med 2014; 62(4):665-675

62 Braido F, Baiardini I, Lacedonia D, et al; Italian Society of Respiratory Medicine (SIMeR). Sleep apnea risk in subjects with asthma with or without comorbid rhinitis. Respir Care 2014;59(12): 1851-1856

63 Teodorescu M, Barnet JH, Hagen EW, Palta M, Young TB, Peppard PE. Association between asthma and risk of developing obstructive sleep apnea. JAMA 2015;313(2):156-164

64 Reid MB, Lännergren J, Westerblad H. Respiratory and limb muscle weakness induced by tumor necrosis factor-alpha: involvement of muscle myofilaments. Am J Respir Crit Care Med 2002;166(4): 479-484

65 Guilleminault C, Quera-Salva MA, Powell N, et al. Nocturnal asthma: snoring, small pharynx and nasal CPAP. Eur Respir J 1988;1(10):902-907

66 National Asthma Education and Prevention Program. Expert Panel Report 3 (EPR-3): Guidelines for the Diagnosis and Management of Asthma-Summary Report 2007. J Allergy Clin Immunol 2007;120 (5, Suppl)S94-S138 